\title{
A RESEARCH ON SIGNIFICANCE OF KALMAN FILTER-APPROACH AS APPLIED IN ELECTRICAL POWER SYSTEM
}

\author{
Adjei-Saforo Kwafo Edmund ${ }^{1}$, Su Hongsheng ${ }^{2}$, Adam Misbawu ${ }^{3}$ \\ ${ }^{1}$ Msc Student, ${ }^{2}$ Professor, Department of Electrical Engineering, School of Automation \& Electrical Engineering, \\ Lanzhou Jiaotong University, Gansu, China \\ ${ }^{3} \mathrm{PhD}$ Student, School of Automation, Wuhan University of Technology, Wuhan, China \\ kingacid17@yahoo.co.uk
}

\begin{abstract}
Recently, AC distribution systems have experienced high harmonic pollution due to the fact that electrical power system parameters are often mixed with noise. In an ideal situation, AC power system is supposed to have a constant frequency at specific voltage but owing to presence of connected nonlinear loads and injection into the grid from non-sinusoidal output active sources etc., have immensely contributed to the total distortion of the both current and voltage waveforms. This has increased the system loses and consequently affected other connected equipment in the system. Therefore there is a need to mitigate these effects if they cannot be eliminated intoto, hence the proposition of Kalman filter. It has been very useful in the aspect of electrical power discipline particularly in harmonic estimation. It has also find it way in the application of power system dynamics, optimal operation and control of motor, relay operation and protection, and also for accurate prediction of short and medium term electrical load forecasting. This paper is to highlight on the significant of Kalman filter methodological approach as adopted in electrical power system.
\end{abstract}

Keywords: Kalman Filter; Electrical Power System; Electrical Load; Harmonic Estimation.

\section{INTRODUCTION}

The presence of harmonic distortion in electrical power system has been linked to nonlinear loads and power electronic equipment and therefore, affecting the normal operation of the system. In actual power system, the output power of renewable energy, the existence of the nonlinear loads and other random process are indirectly changing the system state parameters. Hence, there is a need to present a separation of each vibration signal from random disturbance which is mixed with state parameter of the system. Conventional separation methods are fast Fourier transform (1-6], the minimum mean square error method [7] [8], leastsquare method the adaptive notch filter method [9] etc.

In 1960, American scientists, R. E. Kalman, in the system state space model proposed two simplifying assumptions for mathematical tractability [10]. In making this assumption, he derived an optimal estimate of unknown state of system which was to perform the computation recursively. Thus, his analysis provided accurate analytical solutions for linear filtering problem. However, the power system is dynamic and is intrinsically nonlinear system, therefore improved Kalman filter algorithm such as Extended Kalman Filter (EKF), Unscented Kalman Filter (UKF), and Central Difference Kalman Filter Particle Filter [11] were adopted to solve power system dynamic problems.

As per the persistence development of Kalman filtering theory and improvement of its application in electrical power system, it is mainly applied in the optimal operation and regulation of electrical motor, dynamic state quantification, relay operation and protection, prediction of wind speed, short and medium term load forecasting etc. Therefore, this article seeks to review systematically the application of Kalman filtering theory in power system.

\section{KALMAN FILTERING INDICES}

The Kalman Filter is applied in a dynamic state estimation system. It is a recursive technique and its estimation algorithms exhibit high performance. The two prominent Kalman filter mathematical models of signal in state space form are state variable equation and measurement equation.

\subsection{Random Linear Continuous System}

\section{Mathematical Models And Its Discretization}

Consider the following linear continuous system

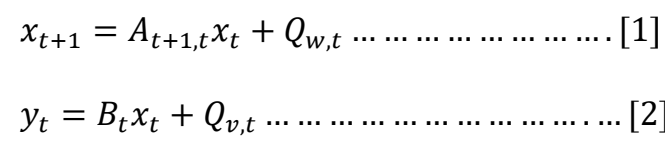

Then, $x_{t}$ is state at time $\mathrm{t}, y_{t}$ is observation at time $\mathrm{t}, A_{t+1, t}$ is invertible transition matrix from state at time $t$ to state at time $t+1, B_{t}$ is the measurement matrix at time $\mathrm{t}, Q_{w, t}$ is covariance matrix of dynamic noise $w_{n}$ and $Q_{v, t}$ is covariance matrix of measurement noise $v_{n}$. 


\subsection{Kalman Filtering Fundamental Equation of Nonlinear Discrete System}

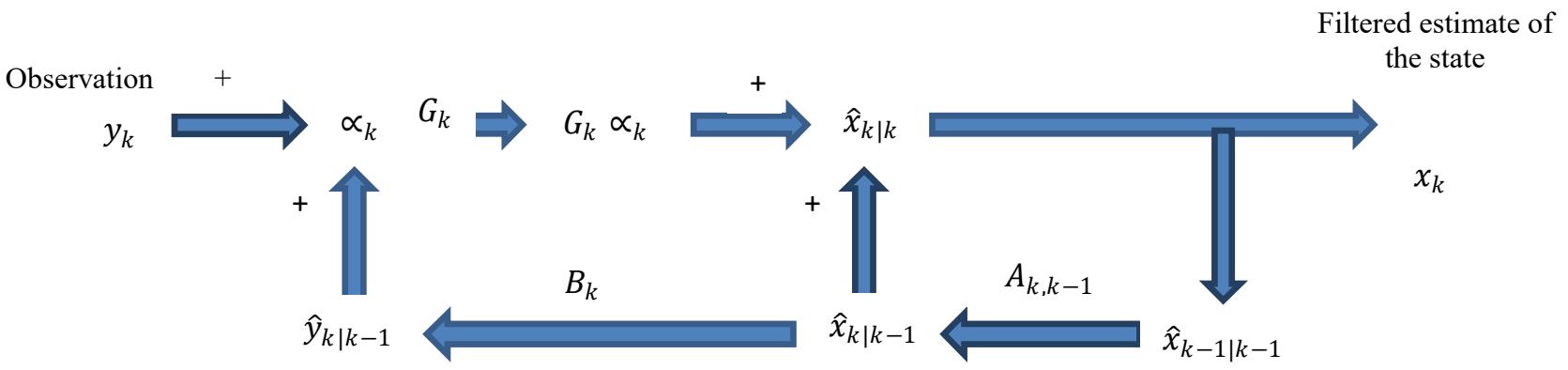

Figure 2.2 Signal-flow graph of the Kalman filter, depicting it as a double-loop feedback system.

In any event, if $k>t$ then the state problem is prediction, if $k=t$ it implies filtering and if $k<t$ implies smoothing. Typically, a smoother is statistically more accurate than both the predictor and filter, as it uses more observables. On the other hand, both prediction and filtering can be performed in real time, whereas smoothing cannot.

A stochastic equation for nonlinear continuous system discretization expression can be obtained by

$\hat{x}_{k+1} \approx A_{k+1, k} \hat{x}_{k \mid k}+Q_{w, k}+\xi_{k} \ldots \ldots \ldots \ldots[3]$

$y_{k} \approx B_{k} x_{k}+Q_{v, k} \ldots \ldots \ldots \ldots \ldots \ldots \ldots \ldots \ldots[4]$

$M_{k+1 \mid k}=A_{k+1, k} M_{k \mid k} A_{k+1, k}^{T}+Q_{w, k} \ldots \ldots \ldots$ [5]

$M_{k \mid k}=M_{k \mid k-1}-G_{k} B_{k} P_{k \mid k-1} \ldots \ldots \ldots \ldots \ldots[6]$

Thus, the pair of equations (5) and (6) provides the means of updating the prediction-error covariance matrix with (6) in particular, commonly referred to as discrete form.

Where:

$G_{k}=P_{k \mid k-1} B_{k}^{T} R_{T}^{-1}$

Again, $\hat{x}_{k \mid k}$ is filtered estimate of the state given observation $y_{1}, y_{2}, \ldots, y_{n} ; \xi_{k}$ is non-random vector, $G_{k}$ is Kalman gain, $M_{k \mid k-1}$ is prediction error covariance matrix, $M_{k \mid k}$ is filtering error covariance matrix and $\propto_{k}$ is innovation process which meet the conditions as well as the discretization process [11].

Therefore, it can be seen that Kalman filter has two interactive computing circuits: update status circuit and measurement circuit, also is the process of prediction and correction.

\section{APPLICATION IN ELECTRICAL POWER SYSTEM FOR SHORT TERM ELECTRICAL LOAD FORECASTING}

Load forecasting is an important part of the normal operation of power systems and control. Adoption of Kalman filter for short-term load forecasting can effectively improve the prediction precision. It discusses about the autocorrelation for load forecasting given its theoretical basis [12], [13].
Short-term load forecasting was established by applying the Kalman filtering theory model to improve the precision of short-term load forecasting. Literature [14] of linear fitting using the least squares method to establish the basic model, load data with three times spline interpolation system parameters identification of Kalman filter and, finally using Kalman filter for historical data preprocessing which corrected the error of measurement. On the basis of considering load dynamic characteristic such as the load system with time-varying coefficient model, the prediction equation to predict the load has obtained good results [15].

Public meteorological forecast affects the power system load and may lead to the deviation in the power load forecasting error. Therefore, based on the theory of the distribution of the random events, literature [16] gives the iteration algorithm of Kalman filter and uses Kalman filtering estimator technology development of meteorological information for power load forecasting. It has the statistical meaning of minimum variance under test of meteorological data and improves the short-term load forecasting accuracy. In view of the weather sensitive load, fuzzy linear model is established using Kalman filter combined with fuzzy reasoning completed parameter estimation which significantly improves the accuracy of the electrical load forecasting. Considering daily variation of load regularity, Kalman filtering gives detailed process of electric power system short term electrical load forecasting [17], [18]. The ultra-short term electrical load forecasting comprises of multiple node-active and node-reactive load variations. With the reference to the use of least squares support vector machine (RLS-SVM) technologies and techniques of Kalman filter node active distribution factor as well as power factor to establish adaptive dynamic prediction model, the results show that both algorithms can meet the system operation speed, robustness and precise prediction [19].

\section{APPLICATION IN STATE ESTIMATION OF ELECTRICAL POWER SYSTEM DYNAMICS}

The operation of electrical power system in aspect of energy management system EMS)system such as monitoring, prediction, safety, evaluation and scheduling control is an important part of the dynamic state estimation due to its closeness to the actual operation of the power systems. It has attracted many attentions of the academic circles. Extended 
Kalman filter, Unscented Kalman Filter etc. are currently used in the system state estimation.

In the 1970s, Debs based on extended Kalman filtering theory, proposed the simplest system model of the dynamic state estimation theory [20].

Masiello etc. [21] also gives the ideas and methods of tracking state estimation. Literature [22] in the phasor measurement unit (PMU) analyzed in detail the measured electromagnetic generator output power equation of motion of the rotor of a generator and an external network on the basis of decoupling. The proposition was based on linear Kalman filtering method of generator dynamic estimation model state variables, and the measurement error and the model of dynamic noise. In literature [23] nonlinear Kalman filter method is adopted.

Based on extended Kalman filtering principle, literature [24] in the state transition equation node status introduced synthetic prediction model with the intelligence of adaptive filtering method to estimate the state of the system, thus, literature [25] established the mathematical model of the dynamic state estimation. Three approaches of numerical method were proposed by Mandal [1995], Lin [2003], Liu [2004] and Han [2008] which included nonlinear Kalman filtering method [23-26].

INEKF (Incorporating nonlinearities of measurement function), the adaptive prediction of the dynamic state estimation AFEKF (the adaptive forecasting method) and smooth plane fuzzy control dynamic state estimation (Sliding surface - enhanced fuzzy control), were adopted to improve the EKF adaptability, robustness of the algorithm and accuracy.

EKF is the method of linearization of nonlinear function approximation. If the system presents strong nonlinear characteristics, then the estimation precision will be seriously declined or even give in to divergence phenomenon. Therefore, Julier et al. [27-28] according to the basic idea of deterministic sampling based on the Unscented transformation (UT) remedied the aforementioned divergence phenomenon. At the same time, Norgaard Ito [29] and [30] based on Stirling polynomial interpolation formula respectively proposed a separate difference filtering and central difference filtering. Later Merwe [31] unified them and called it central difference Kalman filter (CDKF), but also called Sigma point Kalman filter [32].

Apropos of state estimation of electrical power system dynamic, the established dynamic state estimation mathematical model for exploration of the improved algorithm gives way to a new school of thought. . Literature [33] uses No Trace transformation based on UKF method of dynamic power system state estimation which avoided the linearization error brought by the EKF method. That saved the calculation of Jacobian matrix which has the very good convergence and higher than that of EKF method estimation precision and stability. In order to make up for defect of EKF and UKF, literature [34] proposed hybrid Kalman particle filter. The algorithm uses No Trace Kalman filter and EKF as proposal distribution, and which was much closed to the real distribution of approximate expression. Verification of results showed that the power system after a disturbance, can be converge to the real value using MKPF as compared with EKF and UKF which has higher accuracy and stability. It can be seen that hybrid Kalman filter in dynamic state estimation in electrical power system has very good application prospects.

\section{THE ROLE OF POWER QUALITY ANALYSIS}

Power quality includes quality from three aspects namely; the quality of voltage, frequency and waveform. With the development of modern electric power system, the sensitivity of the equipment used and load connected has caused wide attention [35], [36]. Some of the methods for power quality detection are Fourier transform method [3740], Minimum absolute value (also known as further absolute value) state estimation [41-43], Genetic algorithm using wavelet analysis [44], [45] and Teager energy operator (TEO) methods [46]. In view of the above limitations of those methods, Kalman filter used in power quality analysis has advantages of its own. The three basics which follow Kalman filter principle namely; Kalman filter and its extension, and no trace of Kalman filter are summarized with their application in power quality analysis of the status quo [47].

With reference to problem of voltage sag, literature [48] demonstrated method of using the second-order Kalman filter for detection of voltage sag with faster response in terms of speed ,but it is not influenced by unbalanced threephase of harmonic voltage. However, its precision is often unsatisfactory. Literature [49] is proposed the use of linear Kalman filtering error sequence of transient power quality time domain method. The time of disturbances can be determined in real time which is effective for voltage sags, rising amplitude information and improves the accuracy of the detection. However the slow dynamic response is its drawback. Therefore, the literature [50] with compensation amount of time-varying Kalman filter was proposed.

The compensation component of detection of voltage sag with reference to time-varying Kalman filter was first designed with compensation component of Kalman filter model and then residual method was later used to detect voltage mutation, control model transformation, timevarying quantities. Simulation experiments show that the method has faster speed response and it can satisfy the realtime requirement of dynamic voltage restorer. Further, literature [51] gives a voltage disturbance detection based on Kalman filter.

Algorithm adopted for a new model to calculate the effective value of power grid voltage signal can be achieved by setting the voltage threshold, voltage sag and voltage 
bump waveform real-time tracking. This is advantageous for the real-time detection grid disturbance. In addition, the Kalman filter can effectively monitor and predict the voltage flickering as well as the sag [52-55].

Kalman filter especially extended Kalman filter and no trace Kalman filter have been widely applied in the field of frequency tracking [56-59]. Literature [60] introduced robust extended Kalman filter algorithm which gives the precise tracking of fundamental wave frequency. Because the algorithm has a fast response speed and high accuracy, therefore it can effectively suppress the noise power grid as the result of frequency tracking to meet the requirements of power system real-time application. In accordance with literature [58], the plural type of extended Kalman filter (ECKF) algorithm on the basis of literature [61] uses a novel complex type Sigma points based on no trace transform Kalman filter (CSPKF) algorithm for dynamic tracking of instantaneous frequency of power system. This algorithm has the ability to improve greatly the convergent speed.

On the issue of the power system harmonic, Kalman filter had been suggested in the 1990s in application of harmonic measurement [62]. Literature [63], \{64] use Robust expansion exhibition Kalman filtering (REKF) technology for dynamic harmonic state estimation. Also, literature [64] use the artificial neural network combined with improved EKF, as well as, the REKF for dynamic harmonic estimation. Document [65] Proposed that the programming variant of the extended Kalman filtering (PEKF) method to measure harmonics in power system has better performance and efficiency. Literature [66] proposed a three-phase dynamic harmonic state estimation based on Kalman algorithm technology through the decomposition of harmonic current taken the appropriate state variables to effectively judge the branch containing harmonic source. Document [67] uses adaptive Kalman filtering algorithm for harmonic state estimation to select zero matrix as a unit and basic matrix. The adaptive Kalman filter can be between the two basic types of Q matrix model transformation which is a stable state to switch to the transient situation which cannot be quickly bifurcated by problem of the tracking system changes.

\section{APPLICATION IN ELECTRIC POWER SYSTEM RELAY OPERATION AND PROTECTION}

Relay protection in power system make it safe, reliable, stable and guarantees the optimal economic operation of electrical power systems. It improves the reliability for the whole system hence its great significance. Kalman filter in the application of relay operation and protection is mainly embodied in the sensor fault detection and diagnosis as well as the fault signal processing etc. [68].

In Kalman filtering technology and on the basis of hypothesis testing theory, this paper proposes a fault detection method and calculation which indicates that the result of this method is rapid, reliable and highly sensitive. Document [69] highlighted on fault detection (fault current and voltage estimation), fault classification and fault location into five parts. Kalman filter algorithm is introduced in the implementation of microcomputer distance protection. In order to improve the calculation precision of fundamental component in the microcomputer protection and response speed, literature [70] of Kalman filter and the whole Zhou Fu's algorithm is analyzed and compared. The results verified the advantages of Kalman filtering. Document [71] is based on fault detection and diagnosis system of federal Kalman filter in combination with intelligent fault-tolerant controllers which effectively detect the shortcoming of microcomputer relay protection and improve the reliability of microcomputer protection system.

During system failure, the signal often contains a lot of periodic component and harmonic component which might have delayed the convergence rate of the Kalman filter. Therefore, literature [72] proposed a technique which involved the combination of Kalman filter and wavelet transform for fault detection and extraction of fundamental component. The paper used Kalman filter model to estimate fundamental component characteristics and combining the system wavelet transform modulus maxima of high frequency component tracking time using the update of the gain from coefficient and error covariance matrix. Thus, it reduces the response time of the Kalman filtering model thereby guaranteeing the fast response of the microcomputer protection against failure. To sum up, Kalman filter has features of fast response and good filtering effect by meeting the relay operation and protection requirements there by tripping rapidly and accurately.

\section{APPLICATION OF WIND SPEED FORECASTING}

Wind speed prediction of wind farm and the operation of the power system are of great significance. Wind farm volatility-output power is mainly caused by wind speed change, so accurate wind speed prediction can effectively reduce the negative impact of the wind farm to power system [73]. Wind speed forecasting is commonly analyzed using artificial neural network [74], [75], time series method [73], [76], [77] and Kalman filtering method [78-82] etc. Considering the accuracy requirements, the combination of several methods for wind speed forecasting has become a trend.

Document [78] uses Kalman filter techniques and least squares support vector machine (SVM) on the amount of wind power and wind power allocation factor adaptive dynamic prediction based on association rule are implemented directly as a super short term power output of wind farms. The results showed that the proposed prediction method has certain accuracy. Literature [79] based on time series and the Kalman filtering methods, presented two improved algorithm for short-term forecast wind speed. The verification results showed that both algorithms could 
effectively improve the accuracy of the measured wind speed sequence short-term forecasting of wind farms. Document [80] proposed a short-term correction based on Kalman filtering wind farm power prediction model. It used Kalman filtering algorithm of numerical weather forecast output of wind speed data for dynamic correction, contrast analysis which showed that Kalman filtering correction of wind speed data is able to track the change tendency of the actual wind speed data and also, improve the prediction accuracy. In order to make up for the disadvantage of each method, the literature [81] proposed a combination of time series analysis and Kalman filter hybrid algorithm reflecting the sequence established based on time series signal change law of low order model. This directly deduced the Kalman filter state and measurement equations by using Kalman forecast iterative equation to solve the higher order of time sequence model and difficult problems. Document [82] highlight the use of Bayesian - Kerry gold - Kalman model on the basis of multiple wind speed rolling optimization and prediction of algorithm. This approach helped to comprehensively utilize the power in terms of wind speed data for more accurate prediction.

\section{APPLICATION IN MOTOR STATE AND PARAMETER ESTIMATION}

Motor is an electromechanical device which plays an irreplaceable role in power system. Therefore identifying its state and parameter estimation is very important for its efficient operation. Literature [83], from the perspective of the principle of extended Kalman filter algorithm using the stator current and voltagemeasured to deduce the synchronous motor speed to quantify the rotational speed of motor and the stator magnetic flux-linkage. This method can achieve high performance of motor control. In recent years, the Kalman filtering has been used to analyze synchronous motor especially permanent magnet synchronous motor. According to documents [84], [85], extended Kalman filtering (EKF) has been applied in the sensorless control of permanent magnet synchronous motor and good results have been achieved. Literature [86] proposes that using Kalman filter as observer for all-digital fuzzy Direct Torque Control (DTC) system has been carried on the accurate parameter estimation. Thus, all-digital fuzzy speed sensorless control is realized. 0n the detection of stator voltage and current, the application of EKF observer is very accurate in calculation of stator magnetic fluxlinkage of motor, rotor state, speed of the motor and indirect estimation of motor torque. In document [87], the extended Kalman filtering theory and sliding mode structure of the permanent magnet synchronous motor speed observer, has been used accurately to observe the full working condition of the speed and position. The document [88] has extended Kalman filter real-time and multi-scale wavelet transform carried out based on the motor terminal voltage and stator current information on its online estimate. It was discover that diagnosing permanent magnetic field with the algorithm has a better accuracy. Document [89] by a state augmented extended Kalman filtering (AEKF) method for the motor speed, the magnetic pole position and resistance were estimated. The sensorless control system provides good dynamic response characteristics. In document [90], no trace Kalman filter (UKF) was applied to a motor of nonlinear state estimation in the sensorless drive system. It effectively avoided the linearization error and calculation Jacobian matrix. [91-93].

\section{CONCLUSION}

Although the Kalman filter theory proposed has been over half a century but its application in power system cannot be over emphasized. Further, it has been widely applied in telecommunication for satellite position; robotic engineering for estimation of position etc. Its application is numerous so far as engineering is concern. In this paper, according to the characteristics of the Kalman filter and its extension form in the aspects of electric power systems are reviewed and in the field of application. It must be pointed out that Kalman filter has its drawbacks and shortcomings but combining with other intelligent algorithms has become the development trend of the future.

\section{REFERENCE}

[1] R. C. Dugan, M. F. McGranaghan and H. W. Beaty, Electrical Power System Quality, McGraw-Hill, 1996

[2] WEN He, TENG Zhao-sheng, QING Bai-yuan. Hanning self-convolution windows and its application to harmonic analysis [J]. Transactions of China Electrotechnical Society, 2009, 24(2): 164-169.

[3] LIU Chuang, LIU Su-zhen, YANG Qing-xin, et al. Signal processing of electromagnetically induced acoustic emission based on FFT and wavelet packet transform $[\mathrm{J}]$. Transactions of China Electrotechnical Society, 2010, 25(4): 24-28.

[4] HUI Jin, YANG Hong-geng. Harmonics and interharmonics separate-detection method based on estimation of leakage values caused by interharmonics $[\mathrm{J}]$. Transactions of China Electrotechnical Society, 2011, 26(1): 183-190.

[5] XU Yan, ZHANG Xiao-ming, WANG Yu, et al. A new method of spectrum analysis based on DFT [J]. Power System Protection and Control, 2011, 39(11): 38-43.

[6] QIN Si-shi, LIU Qian-jin. Hybrid algorithm for interharmonics measurement based on particle swarm optimization and neural network[J]. Power System Protection and Control, 2011, 39(11): 38-43.

[7] LI Hui-yu, YU Sheng-lin, JI Kan, et al. Study on convergence of adaptive filtering measurement for power signa[J]. Automation of Electric Power Systems, 2007, 31(22): 73-76.

[8] LI Bi-jun, XUE Yu-sheng, GU Jin-wen, et al. Weight function based power system state estimation algorithm [J]. Automation of Electric Power Systems, 1999, 23(8): 32-34.

[9] WU Bin, ZHAO Xue-zeng, TENG Zhi-jun. Detection of power frequency communication signal based on adaptive filter [J]. Automation of Electric Power Systems, 2003, 27(20): 35-39. 
[10]KALMAN R E. A new approach to linear filtering and prediction problems $[\mathrm{J}]$. Transactions of the ASME, Journal of Basic Engineering, 1960, 82(Series D): 35-45.

[11]ZHAO Lin. Nonlinear system filtering theory [M]. Beijing: National Defense Industry Press, 2012: 1-8.

[12] HUELSEMANN S M. Short and ultra-short term load forecast by Kalman filter and autocorrelation[C] // Proceedings of the Universities Power Engineering Conference. Edinburgh (UK): 1998: 497-500.

[13]LI Ming-gan, SUN Jian-li, LIU Pei. Short-term load forecast of power system based on Kalman filter [J]. Relay, 2004, 32(4): 9-12.

[14]ZHANG Min, BAO Hai, YAN Ling, et al. Research on processing of short-term historical data of daily load based on Kalman filter[J]. Power System Technology, 2003, 27(10): 39-42.

[15]MA Jing-bo, YANG Hong-geng. Application of adaptive Kalman filter in power system short-term load forecasting [J]. Power System Technology, 2005, 29(1): 75-79.

[16]LI Peng, REN Zhen, ZHANG Yong-jun. Kalman filter based weather estimator designing [J]. Journal of South China University of Technology: Natural Science Edition, 2002, 30(6): 36-39.

[17] AL-HAMADI H M, SOLIMAN S A. Fuzzy short-term electric load forecasting using Kalman filter [J]. IEE Proc-Gener, Transm, and Distrib, 2006, 153(2): 217227.

[18] GASALDI M, LAMEDICA R, NARDECCHIA A, et al. Short-term forecasting of municipal load through a Kalman filtering based approach[C] // Power Systems Conference and Exposition, 2004: 1453-1458.

[19]HAN Li, HAN Xue-shan, YUN Zhi-hao, et al. Method for ultra-short term multi-node load forecasting $[\mathrm{J}]$. Automation of Electric Power Systems, 2007, 31(21): 30-33.

[20]DEBS A. S., LARSON R E. A dynamic estimator for tracking the state of a power system[J]. IEEE Trans on Power Apparatus and Systems, 1970, 89(7): 16701678.

[21] SCHWEPPE F. C., MASIELLO R. D., A tracking static state estimator $[\mathrm{J}]$. IEEE Trans on Power Apparatus and Systems, 1971, 90(3): 1025-1033.

[22] QIN Xiao-hui, BI Tian-shu, YANG Qi-xun. Dynamic state estimator based on WAMS during power system transient process $[\mathrm{J}]$. Proceedings of the CSEE, 2008, 28(7): 19-24.

[23] MANDAL J. K., SINHA A. K., et al. Incorporating nonlinearities of measurement function in power system dynamic state estimation [J]. IEE ProceedingsGeneration, Transmission and Distribution, 1995, 142(3): 289-296.

[24]HAN Li, HAN Xue-shan, CHEN Fang. Dynamic state estimation in power system based on integrated forecasting model and adaptive filter[J]. Transactions of China Electrotechnical Society, 2008, 23(8): 107-112.

[25] LIU Hui-le, LIU Tian-qi. Status quo and prospect of power system dynamic state estimation [J]. Electric Power Automation Equipment, 2004, 24(12): 73-76.
[26]LIN J. M., HUANG S. J. Application of sliding surface-enhanced fuzzy control for dynamic state estimation of a power system[J]. IEEE Trans on Power Systems, 2003, 18(2): 570-577.

[27] JULIER S. J., UHLMANN J. K. A new approach for filtering nonlinear system[C] // Proc of the 1995 American Control Conference, 1995: 1628-1632.

[28] JULIER S. J., UHLMANN J. K. A new method for the nonlinear transformation of means and covariances in filters and estimators[J]. IEEE Trans on Automatic Control, 2000, 45(3): 477-482.

[29] NORGAARD M, POULSEN N. K. New developments in state estimation for nonlinear systems [J]. Automatica, 2000, 36(11): 1627-1638.

[30]ITO K, XIONG K. Gaussian filters for nonlinear filtering problems $[\mathrm{J}]$. IEEE Trans on Automatic Control, 2000, 45(5): 910-927.

[31]MERWE R V. Sigma-point Kalman filters for probabilistic inference in dynamic state-space models [EB/OL]. [2004]. http://www.cslu.ogi.edu/publications/.

[32][32]WEI Zhi-nong, SUN Guo-qiang, PANG Bo. Application of UKF and SRUKF to power system dynamic state estimation[J]. Proceedings of the CSEE, 2011, 31(16): 74-78.

[33]LI Da-lu, LI Rui, SUN Yuan-zhang. Power system dynamic state estimation with mixed measurements based on UKF [J]. Automation of Electric Power Systems, 2010, 34(17): 17-21.

[34]CHEN Huan-yuan, LIU Xin-dong, SHE Cai-qi. Study on power system dynamic state estimation algorithm [J] Science Technology and Engineering, 2011, 25(11): 6071-6074.

[35]DUGAN R C, MEGRANGHAN M F, BENTY H W. Electrical power system quality[M]. New York: MC Graw-Hill, 1996: 1.

[36] SANNINO A, SVENSSON J, LARSSON T. Powerelectronic solutions to power quality problems [J]. Electric Power Systems Research, 2003, 66(1): 71-82.

[37] SRINIVASAN K. Digital measurement of voltage flicker [J]. IEEE Trans on Power Delivery, 1991, 6(4): 1593-1598.

[38]LI Geng-yin, CHEN Zhi-ye, NING Yu. Two improved algorithms of the fast Fourier transform [J]. Automation of Electric Power Systems, 1997, 21(12): 37-40.

[39]ZHANG Fu-sheng, GENG Zhong-xing, GE Yao-zhong. FFT algorithm with high accuracy for harmonic analysis in power system [J]. Proceedings of the CSEE, 1999, 19(3): 63-66.

[40]XUE Hui, YANG Ren-gang. Precise algorithms for harmonic analysis based on FFT algorithm [J]. Proceedings of the CSEE, 2002, 22(12): 106-110.

[41]SOLIMAN S, EI-HAWARY M. Measurement of power system voltage and flicker levels for power quality analysis: a static LAV state estimation based algorithm[J]. International Journal of Electrical Power \&Energy Systems, 2000, 22(6): 447-450

[42] EL-NAGGAR K M, AL-HASAWI W M. A genetic based algorithm for measurement of power system 
disturbances $[\mathrm{J}]$. Electric Power Systems Research, 2006, 76(9-10): 808-814.

[43] EL-ZONKOLY A M. Power system model validation for power quality assessment applications using genetic algorithm [J]. Expert Systems with Applications, 2005, 29(4): 941-944.

[44] SANTOSO S, POWERS E J, GRADY W M. Electric power quality disturbance detection using wavelet transform analysis[C] // Proceedings of the IEEE-SP International Symposium on Time-Frequency and Time-Scale Analysis, Philadelphia, USA.

[45]HUANG S J, HSIEH C T, HUANG C L. Application of Morlet wavelets to supervise power system disturbances[J]. IEEE Trans on Power Delivery, 1999, 14(1): 235-241.

[46] ABDEL-GALIL T K, EL-SAADANY E F, SALAMA M M A. Online tracking of voltage flicker utilizing energy operator and Hilbert transform[J]. IEEE Trans on Power Delivery, 2004, 19(2): 861-867.

[47] YU Jing-wen, XUE Hui, WEN Bo-ying. A survey on Kalman filtering based methods for power quality analysis [J]. Power System Technology, 2010, 34(2): 97-102.

[48]ELNADY A, SALAMA M M A. Unified approach for mitigating voltage sag and voltage flicker using the DSTATCOM[J]. IEEE Trans on Power Delivery, 2005, 20(2): 992-1000.

[49]ZHANG Jing, XU Zheng. Power quality disturbances detection based on Kalman filter residuals [J]. Proceedings of the CSU-EPSA, 2006, 18(5): 25-30.

[50] YUAN Feng, YANG Hong-geng, LIN Cheng-hui. A method for voltage sag detection based on timevarying Kalman filter with compensation component $[\mathrm{J}]$. Proceedings of the CSEE, 2008, 28(31): 81-86.

[51]REN Wen-lin, ZHAO Qing-sheng, HE Zhi-fang. Detection of voltage disturbance based on Kalman filter algorithm [J]. Water Resources and Power, 2012, 30(11): 198-200.

[52]KAMWA I, SRINIVASAN K. Kalman filter-based technique for combined digital estimation of voltage flicker and phasor in power distribution systems[J]. European Transactions on Electrical Power Engineering, 1993, 3(2): 131-142.

[53] GIRGIS A A, MAKRAM E B. Measurement of voltage flicker magnitude and frequency using a Kalman filtering based approach[C] // Canadian Conference on Electrical and Computer Engineering, Calgary, Canada, 1996.

[54]PEREZ E, BARROS J. An extended Kalman filtering approach for detection and analysis of voltage dips in power systems[J]. Electric Power Systems Research, 2007, 78(4): 618-625.

[55]BARROS J, PEREZ E. A combined wavelet-Kalman filtering scheme for automatic detection and analysis of voltage dips in power systems[C] // 2005 IEEE Russia Power Tech, Petersburg, Russia, 2005.

[56]DASH P K, PRADHAN A K, PANDA G. Frequency estimation of distorted power system signals using extended complex Kalman filter [J]. IEEE Trans on Power Delivery, 1999, 14(3): 761-766.

[57] AUROBINDA R, ASHOK K P, RAO K P. A novel Kalman filter for frequency estimation of distorted signals in power Systems[J]. IEEE Trans on Instrumentation and Measurement, 2002, 51(3): 469479.

[58] DASH P K, JENA R K, PANDA G, et al. An extended complex Kalman filter for frequency measurement of distorted signals $[\mathrm{J}]$. IEEE Trans on Instrumentation and Measurement, 2000, 49(4): 746-753.

[59]HUANG C H, LEE C H, SHIH K J, et al. Frequency estimation of distorted power system signals using a robust algorithm [J]. IEEE Trans on Power Delivery, 2008, 23(1): 41-51.

[60]ZHANG Bin, ZHANG Dong-lai. Adaptive fundamental component extraction and frequency tracking algorithm for power systems[J]. Proceedings of the CSEE, 2011, 31(25): 81-89.

[61]LUO Chen-chi, ZHANG Ming. Frequency tracking of distorted power signal using complex sigma point Kalman filter [J]. Automation of Electric Power Systems, 2008, 32(13): 35-39.

[62]BEIDES H M, HEYDT G T. Dynamic state estimation of power-system harmonics using Kalman filter methodology [J]. IEEE Trans on Power Delivery, 1991, 6(4): 1663-1670.

[63]KUMAR A, DAS B, SHARMA J. Dynamic state estimation of power system harmonics with bad data[J]. Electric Power Components and Systems, 2005, 33(12): 1281-1295.

[64]KUMAR A, DAS B, SHARMA J. Robust dynamic state estimation of power system harmonics [J]. International Journal of Electrical Power \& Energy Systems, 2006, 28(1): 65-74.

[65]ROUTRAY A, PRADHAN A K, RAO K P. A novel Kalman filter for frequency estimation of distorted signals in power systems[J]. IEEE Trans on Instrumentation and Measurement, 2002, 51(3): 469479.

[66] MA Hai-li, GIRGIS A A. Identification and tracking of harmonic source in a power system using a Kalman filter [J]. IEEE Trans on Power Delivery, 1996, 11(3): $1659-1665$.

[67] YU K K C, WATSON N R, ARRILlAGA J. An adaptive Kalman filter for dynamic harmonic state estimation and harmonic injection tracking [J]. IEEE Trans on Power Delivery, 2005, 20(2): 1577-1584.

[68]BIAO Zhao-hong, YU Yan, YU Jiu-xiang. A new algorithm of fault detection [J]. Automation of Electric Power Systems, 1995, 19(4): 39-42.

[69] YU Jiu-xiang. The application of Kalman filtering technique in distance protection [J]. Relay, 1998, 26(4): 20-24.

[70]ZHANG Ju, DONG Jie. Comparison of two algorithms in digital protection $[\mathrm{J}]$. Journal of North China Electric Power University, 2003, 30(4): 6-10.

[71] CHENG Hong-bo, WANG Xun, LUN Li. Sensors' fault tolerant control of microcomputer-based relay protection [J]. Relay, 2007, 35(19): 1-4. 
[72]SUN Xu-xia, GUO Yong-sheng. Wavelet-based Kalman filter for fundamental component [J]. Proceedings of the CSU-EPSA, 2012, 24(4): 93-98.

[73] YANG Xiu-yuan, XIAO Yang, CHEN Shu-yong. Wind speed and generated power forecasting in wind farm [J]. Proceedings of the CSEE, 2005, 25(11): 1-5.

[74]LI Shu-hui, WUNSCH D C, O HAIR E A, et al. using natural networks to estimate wind turbine power generation $[\mathrm{J}]$. IEEE Trans on Energy Conversion, 2001, 16(3): 276-282.

[75]FAN Gao-feng, WANG Wei-sheng, LIU Chun, et al. Wind power prediction based on artificial neural network [J]. Proceedings of the CSEE, 2008, 28(34): 118-123.

[76]BILLINTON R, CHEN H, GHAJAR R. Time-series models for reliability evaluation of power systems including wind energy $[\mathrm{J}]$. Microelectronics and Reliability, 1996, 36(9): 1253-1261.

[77]DING Ming, ZHANG Li-jun, and WU Yi-chun. Wind speed forecast model for wind farms based on time series analysis[J]. Electric Power Automation Equipment, 2005, 25(8): 32-34.

[78] LI Zhi, HAN Xue-shan, HAN Li, et al. An ultra-shortterm wind power forecasting method in regional grids [J]. Automation of Electric Power Systems, 2010, 34(7): 90-94.

[79]PAN Di-fu, LIU Hui, LI Yan-fei. Optimization algorithm of short-term multi-step wind speed forecast [J]. Proceedings of the CSEE, 2008, 28(26): 87-91.

[80]ZHAO Pan, DAI Yi-ping, XIA Jun-rong, et al. A Kalman filter based correction model for short-term wind power prediction [J]. Journal of Xi'an Jiaotong University, 2011, 45(5): 47-51.

[81]PAN Di-fu, LIU Hui, LI Yan-fei. A wind speed forecasting optimization model for wind farms based on time series analysis and Kalman filter algorithm[J]. Power System Technology, 2008, 32(7): 82-86.

[82]QING Xiang-yun, YANG Fu-wen, WANG Xing-yu. Short-term wind speed forecasting for multiple wind farms using Bayesian Kriged Kalman mode[J].Proceedings of the CSEE, 2012, 32(35): 107114.

[83] XU Jin, CHEN Shan-jie. New design of DTC AC motor state observer based on EKF $[\mathrm{J}]$. High Voltage Engineering, 2007, 33(5): 127-130.

[84]BOLOGNANI S, TUBIANA L, ZIGLIOTTO M. Extended Kalman filter tuning in sensorless PMSM drives [J]. IEEE Trans on Industry Applications, 2003, 39(6): 1741-1747.

[85] COMNAC V, CIRSTE M N, MOLDOVEANU F. Sensorless speed and direct torque control of interior permanent magnet synchronous machine based on extended Kalman filter[C] // Proceedings of the IEEE International Symposium on Industrial Electronic, China, 2002: 1142-1147.

[86]CHEN Zhen, LIU Xiang-dong, JIN Yong-qiang, et al. Direct torque control of permanent magnet synchronous motors based on extended Kalman filter observer of flux linkage[J]. Proceedings of the CSEE, 2008, 28(33): 75-81.

[87]LI Jun, LI Yu-zhou. Speed sensorless SVM-DTC for permanent magnet synchronous motors [J]. Proceedings of the CSEE, 2007, 27(3): 28-34.

[88] WEN Chuan-bo, QI Liang. On-line detection method of magnet flux linkage for permanent magnet synchronous motor[J]. Proceedings of the CSU-EPSA, 2010, 22(2): 22-26.

[89]LU Hua-cai, XU Yue-tong. Speed and position estimation algorithm of permanent magnet linear synchronous motor based on augmented extended Kalman filter [J]. Proceedings of the CSEE, 2009, 29(33): 90-94.

[90] YU Pei-qiong, LU Yi-hong, WANG Yong, et al. Research on permanent magnet linear synchronous motor position sensorless control system[J]. Proceedings of the CSEE, 2007, 27(24): 53-57.

[91] JIA Rong, YANG Ke, YUAN Li, et al. Dielectric loss measurement based on Kalman filter and interpolating windowed fast Fourier transform algorithm[J]. Power System Technology, 2007, 31(19): 52-55.

[92]WANG Xing-zhi, YAN Zheng, SHEN Chen, et al. Power grid bad-data detection and identification based on online kernel learning method[J]. Power System Protection and Control, 2012, 40(1): 50-55.

[93] TAN Ping, CAI Zi-xing. Fault diagnosis of Multiprecision sensors in large noise background [J]. Transactions of China Electrotechnical Society, 2012, 27(4): 83-87. 